\title{
Iglesia "en salida". \\ Una aproximación teológico pastoral al concepto de Iglesia en Evangelii Gaudium
}

\author{
Cristián Roncagliolo \\ FACULTAD DE TEOLOGÍA \\ PONTIFICIA UNIVERSIDAD CATÓLICA DE CHILE \\ padrecristian@gmail.com
}

\begin{abstract}
Resumen: El presente artículo es un aproximación a la eclesiología de comunión en Evangelii Gaudium, que busca explicar qué se entiende por comunión misionera y cuáles son las consecuencias pastorales que emanan de dicha comprensión. Estas últimas están sistematizadas en tres paradigmas o criterios que denotan la novedad planteada por Francisco, siendo sobresaliente el hecho de que comprende la comunión como lugar preeminente para la misión. Esta forma de comprender la Iglesia devela una crítica al modo como se ha autocomprendido la comunidad de los discípulos y una invitación a una auténtica conversión pastoral para la misión.
\end{abstract}

Palabras clave: Iglesia, misión, comunión, conversión pastoral.

Abstract: This article studies the communion ecclesiology found in Evangelii Gaudium. Explains what the document understands by missionary communion and its pastoral consequences. Three pastoral models follow that show Pope Francis' vision, specially mainly his thought of communion for mission.

Keywords: Church, Mission, Communion, Pastoral conversion.

"Este texto corresponde a la Lección dictada el día 15 de abril, con ocasión de la inauguración del año académico 2014 de la Facultad de Teología de la Pontificia Universidad Católica de Chile”.

La misión pastoral de la Iglesia está íntimamente ligada a cómo ella se entiende a sí misma. Esta autocomprensión no ha de buscar su fundamento en la contingencia histórica ni en un constructivismo mutable 
-sin negar que estos factores contribuyan a la mencionada auto comprensión-, sino que en Jesucristo, quien es su Fundador. Por ello, al momento de preguntarnos por la identidad y el sentido de la Iglesia, tenemos que remitirnos a la voluntad "creadora" de Cristo y a la misión que le quiso confiar a su obra.

El Concilio Vaticano II, haciéndose cargo de esta problemática, y entendiendo la exigencia que el contexto histórico hacía a la comunidad de los discípulos en vista a transparentar de manera más nítida su ser original, buscó responder a la pregunta acerca de cómo se autocomprende la Iglesia y su consecuente misión. En esta dinámica de la auto comprensión se hace nítida progresivamente la denominada "eclesiología de comunión” como una matriz que, en sí misma explica, de manera amplia y profunda, la naturaleza de la Iglesia.

Esta “eclesiología de comunión” encuentra una recepción madura y novedosa en Evangelii Gaudium. La Exhortación Apostólica, en efecto, hace una síntesis y, al mismo tiempo, una propuesta integrando las dimensiones propias de la Iglesia: ser una comunidad de fe, esperanza y caridad (de filiación en Cristo), que expresa su misión, siendo un signo externo de esa unidad viva (de fraternidad en Cristo), pero que se desarrolla en vista de la misión propia de la comunidad de los discípulos, que es evangelizar (de anuncio de Cristo), porque la comunión "esencialmente se configura como comunión misionera” (EG 23).

Así, la recepción de la "eclesiología de comunión” en Evangelii Gaudium, junto con ser coherente con el Vaticano II, resulta una verdadera provocación a la praxis de la Iglesia, que ha vivido un desarrollo eclesiológico postconciliar centrado en la comunión, pero con una creciente tendencia al "enclaustramiento", a un "hacer" de "autopreservación" y de "vitalización interna", más que a un desarrollo evangelizador, que sitúe la misión de la Iglesia "fuera de sí misma".

Las presentes líneas, junto con hacer una breve exposición de los aspectos centrales de la "eclesiología de comunión”, y de su concreción pastoral, visibilizará de qué manera la reciente Exhortación Apostólica es una contribución novedosa a la autocomprensión de la Iglesia, y de su consecuente acción pastoral, mostrándola con una identidad claramente misionera. Para evidenciar estos aportes propondremos algunos criterios o paradigmas que emergen de la propuesta de Francisco y que, a nuestro juicio, son un aporte a la "criteriología" pastoral. En este camino, no 
obviaremos, finalmente, poner de relieve que este Documento, en su mirada de la Iglesia, tiene un antecedente genético en Aparecida.

\section{LA IGLESIA: SIGNO E INSTRUMENTO DE COMUNIÓN}

La “eclesiología de comunión” es considerada por un importante grupo de teólogos como la innovación más trascendente para la eclesiología postconciliar y para la vida de la Iglesia, especialmente a partir del Sínodo de los Obispos de 1985, que la denominó oficialmente como el concepto clave para comprender todo el acontecimiento conciliar ${ }^{1}$. Esto es relevante porque el concepto de Iglesia (que explica su naturaleza, el "quién es") explicita la misión de la misma (el "para qué"). Por ello, el punto de partida es preguntarnos qué se entiende por "eclesiología de comunión" en el Vaticano II². $^{2}$.

Iglesia, sacramento de comunión

Un primer acercamiento permite dilucidar que esta eclesiología expresa el ser sacramental de la Iglesia y comporta una realidad orgánica constituida por lazos teológico-espirituales que la constituyen como una "comunidad de fe, esperanza y amor" (LG 8). Por tanto, cuando hablamos de "eclesiología de comunión” no hacemos referencia a una comprensión eclesial de carácter organizativo o de reparto de funciones o de poderes, sino, esencialmente, como una comunión con Dios por Cristo en el Espíritu Santo. La Iglesia es comunión porque hunde sus raíces en la comunión trinitaria ${ }^{3}$, siendo una misteriosa extensión de ella en el tiempo (cf. LG 4). De esta manera, la comunión trinitaria "se abre a la historia: al ser recibida

1 Cf. Segunda Asamblea General Extraordinaria del Sínodo de los Obispos, Relación final Ecclesia sub Verbo Dei mysteria Christi celebrans pro salute mundi, 7 de diciembre de 1985, en Enchiridion del Sinodo dei Vescovi (EDB, Bologna, 2005). C.1. Como se podrá observar esta investigación comprende a la Iglesia como una "comunión para el servicio", en el sentido que no se puede entender la dimensión comunional de la Iglesia como "ensimismada", sino, por el contrario, inserta en un dinamismo "extrovertido", de servicio, de salir de sí misma para dar vida al mundo (cf. S. Dianich, Iglesia en Misión. Hacia una eclesiología dinámica [Sígueme, Salamanca, 1988]).

2 Cf. A. Antón, Eclesiología post conciliar: esperanzas, resultados y perspectivas (Sígueme, Salamanca, 1989) $181 \mathrm{~s}$.

3 Cf. J. Rigal, Descubrir la Iglesia (Secretariado Trinitario, Salamanca, 2001) 72. 
por el hombre esa comunión rompe, desde lo más profundo, su soledad haciéndolo hijo de Dios y hermano de los hombres"4.

Consecuencialmente, la Iglesia comunión no está constituida, en primer lugar, por estructuras, sino que es un realidad mistérica que adquiere concreción en la comunidad viva de los discípulos, quienes no se agrupan por simples razones de afinidad, ni siquiera con vistas a una mayor eficacia apostólica ni funcional, sino porque han sido convocados por Cristo (cf. LG 8) para estar en comunión con Él y por eso es "signo e instrumento de la unión íntima con Dios” (LG 1) [filiación]. Él es su fundador, que crea la Iglesia para que sea el Nuevo Israel de Dios (cf. LG 9) [fraternidad]; y es su fundamento, siendo la cabeza que convoca a la unidad en un solo cuerpo (cf. Col 1, 18) (cf. LG 9).

Iglesia, ícono de la Trinidad en la historia

La comunión de Dios y con Dios se vuelve, entonces, en el principio de la unidad entre los hermanos. Así, la comunión trinitaria se despliega en la Iglesia, y a través de ella, presentándose como el fundamento para su orden y para articular de modo correcto la unidad en la diversidad en el cuerpo eclesial. En palabras de H. De Lubac la Iglesia es "mensajera y artífice de unidad" 5 . Esta comunión se verifica en varios niveles: entre los miembros (cf. LG 4, 13), entre quienes ejercitan diversas funciones (cf. LG 32), entre la Iglesia universal y las iglesias particulares (cf. LG 10) y, en modo especial, entre el Sucesor de Pedro y el colegio episcopal (cf. LG 21, 22) ${ }^{6}$.

Porque su fundamento está en la Trinidad, la comunión adquiere una amplitud ilimitada. No se trata solamente de la comunión de los hombres con Dios, sino que también genera la comunión de los hombres entre sí: signo e instrumento "de la unidad de todo el género humano" (LG 1). Al mismo tiempo, por ser relacional, la comunión se convierte en misión: "Anunciar y establecer en todos los pueblos el Reino de Cristo y de Dios" (LG 5), abriéndose a un horizonte sin límites, por lo cual la Iglesia naturalmente no puede vivir replegada sobre sí misma, sino que debe atestiguar y comunicar (cf. 1 Jn 1, 1-4) el Misterio que

\footnotetext{
4 E. Bueno, Eclesiología (BAC, Madrid, 1998) 77.

5 H. De Lubac, Meditación sobre la Iglesia (Encuentro, Madrid, 1988) 144.

6 Cf. S. Pié-Ninot, Eclesiología. La sacramentalidad de la comunidad cristiana (Sígueme, Salamanca, 2007) 168.
} 
la constituye y le da la vida ${ }^{7}$. De ahí que esta comprensión eclesiológica también tenga honda repercusión en la misión de la Iglesia en el mundo.

Sentido relacional y misionero de la Iglesia

La Iglesia recibió de los apóstoles el solemne mandato de "anunciar la verdad que nos salva para cumplirlo hasta los confines de la tierra” (LG 17). Mediante la predicación del Evangelio y la comunicación del Misterio de la Salvación, la Iglesia atrae a los oyentes a la fe y a la confesión de la misma; mediante el anuncio de que Cristo es la plenitud de lo humano y es camino de felicidad, la Iglesia ilumina el peregrinar de todos los pueblos y los atrae, más allá de su credo. Esta misión brota de la naturaleza comunional de la Iglesia y, por tanto, no solo implica anunciar, sino "atraer" hacia una realidad llena de sentido y que plenifica la vida del hombre. De ahí que la identidad misma de la Iglesia la empuja a servir al mundo buscando hacer viva la unidad que la explica y que la impele a su acción.

Así dicho, no es posible comprender esta misión evangelizadora, connatural a la Iglesia, sin una comprensión relacional y proexistente (misionera) de su ser comunión. Por ello, una mirada completa de la eclesiología develada en la Lumen gentium exige reconocer en la Gaudium et spes un complemento indispensable, "la otra cara de la misma moneda", que permite explicar la totalidad del ser y quehacer de la comunidad viva de los discípulos.

Con los principios rectores someramente enunciados, ¿de qué manera Evangelii Gaudium acoge la "eclesiología de comunión"? ¿Cómo este Documento enriquece la comprensión de Iglesia, en cuanto Misterio de comunión?

\section{LA IGLESIA EN EVANGELII GAUDIUM ${ }^{8}$}

En su primera Exhortación Apostólica, Francisco proporciona una reflexión pastoral novedosa sobre la mencionada eclesiología de comu-

\footnotetext{
Cf. J. Rigal, Descubrir la Iglesia, 72.
}

8 En este capítulo se insertarán notas del Documento de Aparecida referidas a nuestro tema, dada la relevancia de este texto para el concierto latinoamericano. Estas notas revelarán que en el Documento de Aparecida emerge, aunque no de manera orgánica, la comprensión de la Iglesia como una "Comunión misionera". 
nión, en sintonía con la comprensión conciliar, poniendo su acento en la dimensión "extrovertida". Al respecto, señala que "la intimidad de la Iglesia con Jesús es una intimidad itinerante, y la comunión esencialmente se configura como comunión misionera” (EG 23). Desde este prisma, el Papa entiende a la Iglesia volcada a la evangelización, como una comunión dinámica, abierta y en salida.

Esta comprensión, en plena coherencia con la naturaleza del Cuerpo de Cristo, reclama una revolucionaria "conversión pastoral" (EG 25), que lleve a que todas las estructuras de la Iglesia se transformen en instrumentos adecuados o cauces expeditos para "la evangelización del mundo actual, más que para la autopreservación” (EG 27). En efecto, "fiel al modelo del Maestro, es vital que hoy la Iglesia salga a anunciar el Evangelio a todos, en todos los lugares, en todas las ocasiones" (EG 23).

Crítica a un modelo pastoral

La propuesta de una Iglesia en "dinamismo de salida" (EG 20) -o "Iglesia extrovertida" 10 -, junto con ser novedosa, devela una crítica al modo como ha sido comprendida, en no pocas ocasiones, la "eclesiología de comunión”, y la consecuente pastoral que de ella brota. La crítica pareciera apuntar a que expresiones de esta eclesiología han sido implementadas pastoralmente con características "narcisas", "autopreservantes" y con un marcado acento intraeclesial. En efecto, el foco de atención ha estado, con preeminencia, en la organización de la Iglesia misma -en sus estructuras- más que en las personas que la constituyen, en los planes pastorales más que en el Evangelio que se debe anunciar, postergando, paradójicamente, el sentido misionero que explica el ser de la Iglesia.

La realidad descrita ha favorecido el "enclaustramiento" de muchos bautizados en los límites internos de las parroquias, movimientos u organizaciones eclesiales. Al respecto, señala Francisco que "si bien se percibe una participación de muchos en los ministerios laicales, este compromiso no se refleja en la penetración de los valores cristianos en el mundo social, político y económico” (EG 10). Esto conlleva la con-

9 Aparecida, al respecto, señala que "la comunión y la misión están profundamente unidas entre si... la comunión es misionera y la misión es para la comunión” (DA 163).

10 Por ello, podemos hablar de una eclesiología extrovertida, es decir, "en el mundo" para servirlo (S. DiAnICH, Iglesia extrovertida: investigación sobre el cambio de la eclesiología contemporánea [Sígueme, Salamanca, 1991]). 
tradictoria situación de que los discípulos, muchas veces, "se limitan a tareas intraeclesiales sin un compromiso real por la aplicación del Evangelio a la transformación de la sociedad" (EG 10), olvidando que la vida y la acción evangelizadora de la "Comunión misionera" transcurren principalmente en los diversos escenarios de la historia, en los que el discípulo está llamado a ser "atractivo", a ser "luz", a ser "sal".

\section{Eclesiología de comunión y pastoral de conjunto}

Este desarrollo eclesiológico "introvertido" no es un fruto "veleidoso", sino que ha tenido como motivación fortalecer la comunión interna de la Iglesia -y la comunión con otras comunidades eclesiales no católicasy la participación de sus miembros, localizando los lugares de encuentro con Cristo $-\mathrm{y}$ con los hermanos $-{ }^{11}$ en las "formas" por medio de las

11 Respecto al tema de los "lugares de encuentro con Cristo", Aparecida proporciona una interesante óptica, entendiéndolo como una experiencia personal -y también comunitaria- con Dios, particularmente rica y no restringida a un concepto abstracto. Hay aspectos particularmente concretos y sustanciales: que el encuentro es entre personas; que cada uno aporta sus riquezas para ser un don para el otro (un encuentro naturalmente proexistente donde hay un "otro" hacia donde fluye la existencia); que este encuentro con Cristo da origen a la iniciación cristiana; que el Kerigma será el hilo conductor del proceso que culmina en la madurez humana y espiritual del discípulo (cf. DA 278a); que este encuentro es la raíz de la comunión discipular con Dios Trino, en Jesucristo, y con los otros discípulos; que esta experiencia existencial de encuentro de la persona de Jesucristo - que es todo don- con la persona humana, hace que esta última camine progresivamente hacia una donación vivencial en una doble dirección: hacia Dios y hacia los "otros" (cf. DA 156).

¿Dónde se puede encontrar privilegiadamente a Jesús?, o en otros términos, ¿cuáles son los lugares, las personas, los dones que hablan de Jesús, que ponen en comunión con él y permiten ser discípulos y misioneros suyos? De una manera prevalente, aunque no excluyente, y siguiendo la senda trazada por Ecclesia in America, la V Conferencia privilegia una serie de "lugares" de encuentro del Señor con sus discípulos, teniendo como marco básico para su realización la fe recibida, la mediación de la Iglesia, "casa" de los discípulos (cf. DA 246), y la búsqueda de Cristo, que no se puede reducir a algo meramente abstracto (cf. EA 12), sino que debe ampliarse valorando la experiencia personal y lo vivencial, considerando los encuentros también en cuanto estos sean significativos para la persona (cf. DA 55). Con estos presupuestos, los lugares de encuentro concitados por Aparecida son: la fe recibida en la Iglesia (cf. DA 246), la Escritura (cf. DA 247), la Liturgia (cf. DA 250), la Eucaristía (cf. DA 251), el Sacramento de la Reconciliación (cf. DA 252), la oración personal y comunitaria (cf. DA 255), la comunidad (cf. DA 256), los pobres, afligidos y enfermos (cf. DA 257), la piedad popular (cf. DA 258), la Virgen María (cf. DA 270) y la devoción a los apóstoles y santos (cf. DA 273) 
cuales se manifiesta la comunidad de los discípulos - en el "cómo" se encarna la Iglesia - en un momento de la historia o en un contexto social determinado.

La reminiscencia de esta comprensión "enclaustrada" de la Iglesia, a modo de hipótesis, la ubico en una parcial interpretación de la denominada Pastoral de Conjunto y su relación con la "eclesiología de comunión”. Sin poder detenerme en un tema que requiere de un estudio más profundo, la señalada interpretación hace creer que estar en "comunión" implica, para quienes siguen esta lógica, lograr una sintonía mayor con el plan programático de la diócesis u organización eclesial -con la "hoja de ruta"-, tendiendo hacia un creciente centralismo, en desmedro de la dimensión carismática, y confundiendo el concepto teológico de comunión con el de uniformidad.

La misión como lugar de comunión

La denominada comunión misionera subraya como lugar esencial para la comunión no primeramente lo "programático", sino lo "paradigmático". Así, lo que constituye la comunión no es el cumplimiento riguroso de un itinerario fraguado por una organización -y que rápidamente queda obsoleto en un mundo que cambia vertiginosamente-, ni es la uniformidad que puede pretender esa estructura -sin desmerecer el valor de las orientaciones comunes-, ni es el centralismo de la gestión pastoral -que ubica al Ordenado como "el lugar" de la comunión-, sino es la comúnmisión que brota de la unidad entrañable con el Señor, que se verifica en los "lugares de encuentro" con Cristo - la fe recibida en la Iglesia, la Eucaristía, los otros Sacramentos, la Sagrada Escritura, etc.-, y que se fortalece en la medida en que sus miembros, diversos por antonomasia, dirigen la mirada al "corazón del Evangelio" (EG 130) ${ }^{12}$.

Esta acentuación de la "comunión en la misión” implica un giro copernicano que rompe la inercia pastoral de los decenios precedentes, la cual concentró sus esfuerzos en forjar la comunión ad intra, aglutinan-

(Cf. C. Roncagliolo, El discipulado en Aparecida. Estudio de un tema central en la $V$ Conferencia, Credo-Ediciones [Saarbrücken, Alemania, 2013, 75s.]).

12 El Documento de Aparecida señala que el confirmar, renovar y revitalizar la novedad del Evangelio "no depende tanto de grandes programas o estructuras, sino de hombres y mujeres nuevos que encarnen dicha tradición y novedad como discípulos de Jesucristo y misioneros de su Reino" (DA 11). 
do a los miembros de la Iglesia en torno a programas de características "monocordes", o bajo el alero de estructuras que, en nombre de la comunión, progresivamente se volvieron centralistas y suspicaces frente a todo modo de acción pastoral que estuviera fuera de su radio. Al mismo tiempo, interpela a una praxis pastoral que progresivamente se ha sostenido en las "grandes estructuras", en los "grandes planes", en las pertenencias a lo "macro". Estas "megaestructuras" en vez de ser subsidiarias de la acción pastoral de las comunidades vivas de la Iglesia, terminan convirtiéndose en estructuras que deben justificar su existencia, generando un complejo entramado, en el que se persigue gestar, aunque no se quiera, la comunión con la estructura misma más que con la misión que la explica, con la "hoja de ruta más que con la ruta misma" (EG 82).

La comunión es diversidad

Un aspecto relevante y provocativo lo encontramos en el "cómo", desde la clave de la "Comunión misionera", se comprende la "unidad" y la "diversidad" de la Iglesia. El Evangelio, en efecto, "se transmite de formas tan diversas, que sería imposible describirlas o catalogarlas, donde el Pueblo de Dios, con sus innumerables gestos y signos, es sujeto colectivo" (EG 129), por lo que una excesiva centralización complica la vida de la Iglesia y la dinámica misionera (cf. EG 32).

Considerando lo anterior, se propone una evangelización que se concentra en lo esencial, y que no se ve amenazada por la diversidad, al considerar que "esa variedad ayuda a que se manifiesten y desarrollen mejor los diversos aspectos de la inagotable riqueza del Evangelio" (EG 40). Esta variedad, en efecto, es armonizada por el Espíritu Santo que "suscita una múltiple y diversa riqueza de dones y, al mismo tiempo, constituye una unidad que nunca es uniformidad, sino multiforme armonía que atrae" (EG 117). Es el mismo Espíritu quien "enriquece a toda la Iglesia evangelizadora con distintos carismas [...] para renovar y edificar la Iglesia” (EG 130). Así, las diferencias entre personas y comunidades, entre iglesias particulares y movimientos, que a veces resultan incomodas, no son una amenaza para la unidad, porque es el Espíritu Santo - principio de unidad-, quien suscita esa diversidad y, al mismo tiempo, puede convertirla "en un dinamismo evangelizador que actúa por atracción [...] Solo Él puede suscitar la diversidad, la pluralidad, la multiplicidad y, al mismo tiempo, realizar la unidad" (EG 131). 
La comunión no es centralismo

En consonancia con lo anterior, emerge otra arista del problema, propia de la "introversión eclesial" y que puede ser una verdadera "enfermedad" pastoral: "cuando somos nosotros quienes queremos construir la unidad con nuestros planes humanos, terminamos por imponer la uniformidad, la homologación. Esto no ayuda a la misión de la Iglesia” (EG 131).

Con ello, provocadoramente se pone en discusión el enfoque que se le da a los planes o itinerarios pastorales, tantas veces monolíticos y uniformes, que tienen la pretensión de ser el lugar donde se genera la comunión de la Iglesia. Esa comprensión, ampliamente difundida hoy, puede ser una suerte de "cuello de botella", porque segrega a los discípulos misioneros, poniendo en cuestión su vínculo de comunión, por el solo hecho de que su carisma no sintoniza con el programa pastoral; y también puede ser un obstáculo a la evangelización porque, tantas veces, persigue un centralismo que no se condice con la naturaleza de la Iglesia. A eso pareciera referir Francisco cuando afirma que "hay estructuras eclesiales que pueden llegar a condicionar un dinamismo evangelizador" (EG 26). Por ello, se hace urgente "ser audaces y creativos en esa tarea de repensar los objetivos de las estructuras, el estilo y los métodos evangelizadores de las propias comunidades" (EG 33). No parece arriesgado afirmar que detrás de esta renovación misionera de las estructuras está la convicción de que ellas han de ser, más que centralistas, "subsidiarias" al servicio de la acción evangelizadora de la Iglesia particular y de los bautizados.

Los bautizados como protagonistas de la evangelización

La propuesta de la "Comunión misionera" tiene su fundamento primero, no en el Sacramento del orden, sino en el bautismo (cf. EG 103), de donde proviene "la gran dignidad" (EG 104) del cristiano, y que lo constituye en discípulo misionero. En efecto, "en todos los bautizados, desde el primero hasta el último, actúa la fuerza santificadora del Espíritu que impulsa a Evangelizar" (EG 119) ${ }^{13}$, por lo que la vitalidad

13 "La vida en el Espíritu no nos encierra en una intimidad cómoda, sino que nos convierte en personas generosas y creativas, felices en el anuncio y el servicio misionero. Nos vuelve comprometidos con los reclamos de la realidad y capaces de encontrarle un profundo significado a todo lo que nos toca hacer por la Iglesia y por el mundo" (DA 285). 
de la Iglesia está en la fuerza que proviene del bautismo que empuja a los discípulos a anunciar la savia y el fervor del Evangelio "en cualquier lugar: en la calle, en la plaza, en el trabajo, en el camino” (EG 127). La nueva evangelización, desde esta perspectiva, implica "un nuevo protagonismo de cada uno de los bautizados [...] Ya no decimos que somos discípulos y misioneros, sino que somos siempre discípulos misioneros" $(E G 120)^{14}$, que sustentan su fuerza evangelizadora en la primacía de la gracia (cf. EG 112).

Desde esta lógica, el seguimiento de Cristo exige hoy una comprensión integral del ser "discípulo misionero" (cf. EG 14), ampliando el paradigma de cristiano que ha primado prácticamente en los últimos decenios y que, plásticamente, se lo caracteriza como el "agente pastoral”, es decir, aquella persona que está íntimamente vinculada con las estructuras de la Iglesia. Este modelo ha contribuido a la contradictoria situación de que, mientras más inserto se está en la vida intraeclesial -movimientos, parroquias, comunidades, etc.- se es considerado un mejor ejemplo de cristiano y de "hombre" o "mujer" de Iglesia. La distorsión está en que el valor de un laico esta supeditado equívocamente a su participación en la vida de la Iglesia. Un ejemplo de ello está en el denominado "protagonismo laical", que se ha traducido en la inserción de los laicos en la estructura de la Iglesia, en los canales de participación, más que en un real protagonismo de los mismos en la transformación del mundo en vista del Reino.

El resultado de este fenómeno es, entre otras cosas, una valorización parcial de la vocación laical y del acontecer cotidiano de la inmensa mayoría de los bautizados, que viven, muchos con ardor y heroísmo, su vida cristiana fuera de las estructuras tradicionales de la Iglesia. Este fenómeno ha contribuido, de alguna manera, al distanciamiento y, por qué no decirlo, al divorcio con la postmodernidad -con sus lenguajes, sus coordenadas, sus preguntas- porque en el horizonte del cristiano y de su misión no está primeramente la historia, sino su misma comunidad, favoreciendo la creciente introversión eclesial.

Pero este protagonismo "bautismal" descrito no conlleva una comprensión secularista, incapaz de reconocer el valor del Sacramento del

14 "En virtud del Bautismo y la Confirmación, somos llamados a ser discípulos misioneros de Jesucristo" (DA 153). 
Orden y marcada por la dialéctica narcisa $-y$ profundamente introvertida- acerca de quién tiene el "poder" en la Iglesia, sino que implica un correcto reconocimiento del insustituible valor de los discípulos "ordenados", particularmente en su servicio a "la santificación de los miembros del Cuerpo Místico de Cristo” (EG 104), ayudando a que cada bautizado desarrolle la función de anunciar y testimoniar, de mostrar lo "atractivo" del Evangelio, para que muchos crean y se conviertan (cf. EG 104). También implica el reconocimiento de que el obispo diocesano, en cuanto pastor de la Iglesia particular y primer responsable de fomentar la comunión misionera, está al servicio de la unidad de los diversos, de animar en la fe y en la misión a los discípulos en sus variados lugares de evangelización y resguardando su legítima autonomía (cf. EG 31).

\section{Una Iglesia "en salida"}

Lejos de todo intimismo, la propuesta descrita pone el foco de la Iglesia "fuera de sí", dispuesta a "salir de la propia comodidad y atreverse a llegar a todas las periferias que necesitan la luz del Evangelio" (EG 20), asumiendo "la dinámica del éxodo y del don, del salir de sí, del caminar y sembrar siempre de nuevo, siempre más allá” (EG 21). Por eso Francisco afirma, con audacia inusitada, que prefiere "una Iglesia accidentada, herida y manchada por salir a la calle, antes que una iglesia enferma por el encierro y la comodidad de aferrarse a las propias seguridades" (EG 49), una Iglesia que "salga" a las periferias, más que una temerosa de equivocarse y sometida a estructuras anquilosantes.

Progresivamente, emerge la comprensión de una Iglesia más "carismática" que "estructural", que sin desconocer el valor de su necesaria organización interna, se revitaliza no por sus innumerables esfuerzos estructuralistas, ni por sus organizaciones y programas, sino porque la fuerza le proviene del Espíritu Santo, que alienta y unifica la misión común de los diversos, obligándola a "expropiarse”, a desposeerse de sí misma, buscando ser más para el "Otro" y para los "otros", porque su misión está "fuera de sî" ${ }^{15}$. Resulta evidente que, para la realización de

15 Esta expresión se usa análogamente a partir de lo afirmado por H. von Balthasar, quien buscando responder a la pregunta sobre qué significa ser cristiano, y en el contexto de su comprensión de la Iglesia, señala que "el cristiano debe aprender a profundizar en su expropiación. Después de haber sido liberado por Cristo, debe seguir orando para pedir desposeimiento de sí" (H. U. von BaLTHASAR, Quién es cristiano, Sígueme, Salamanca, 2000, 122). 
esta propuesta de una "Iglesia en salida", es necesaria una "conversión pastoral" que asuma que "toda renovación en el seno de la Iglesia debe tender a la misión como objetivo para no caer presa de una especie de introversión eclesial" (EG 27); y que procure que todas las estructuras eclesiales se vuelvan más misioneras ${ }^{16}$.

\section{Aproximaciones teOlÓgico-PAStORALES}

Evangelii Gaudium es una sugerente invitación a profundizar nuestra comprensión de la Iglesia $-\mathrm{y}$ de su pastoral-. Pero particularmente su propuesta de una Iglesia "en salida" enriquece diversos ámbitos de la reflexión teológica. Para los fines de esta exposición, y a modo de epílogo, veremos algunas de sus contribuciones a la Teología pastoral, particularmente al campo de la "Criteriología".

Parece necesaria una breve explicación. Entendemos por "Criteriología" aquellos "paradigmas" comunes a todas las acciones de la Iglesia para que sean de verdad tales y que "han de ser exigencia a la hora de realizar acciones eclesiales, a la hora de optar por ellas y a la hora de hacer cualquier tipo de propuestas pastorales" ${ }^{17}$. En palabras del profesor Sergio Pintor, estos son necesarios "para discernir si la singular acción pastoral se desarrolla y se realiza en una correcta perspectiva teológica y en una auténtica visión de fe" ${ }^{18}$. A la luz de estos criterios debe ser reflexionada, proyectada, realizada, verificada y modificada toda acción pastoral. Por tanto, ellos deben estar presentes en todas las etapas de la metodología de la acción pastoral.

A continuación enunciaremos tres criterios o paradigmas que, desde la óptica de la Iglesia "en salida", se presentan como una contribución para la acción pastoral de la "Comunión misionera".

Comunión en la misión

Como señala Evangelii Gaudium, el Espíritu Santo es "quien transforma nuestros corazones y nos hace capaces de entrar en la comunión perfecta de la Santísima Trinidad, donde todo encuentra su unidad. Él construye

\footnotetext{
16 "La conversión pastoral de nuestras comunidades exige que se pase de una pastoral de mera conservación a una pastoral decididamente misionera" (DA 370).

17 J. Ramos, Teología pastoral, (BAC, Madrid, 1999) 101.

18 S. Pintor, L'uomo, via de la Chiesa, (EDB, Bologna, 1992) 93.
} 
la comunión y la armonía del Pueblo de Dios" (EG 117). Así, la comunión de la Iglesia es, en primer lugar, un don que posibilita que los bautizados manifiesten su fraternidad y hagan circular la caridad. Pero también la comunión es un desafío que compromete a todos los discípulos en visibilizar que la Iglesia es signo de la unidad de los hombres con Dios y entre sí (cf. LG 1), lo que implica que la rica pluralidad de personas y de dones, de iniciativas y de proyectos que constituyen la Iglesia están al servicio de la comunión.

Con este antecedente, la propuesta de la Iglesia "en salida" privilegia la misión como "lugar" paradigmático para gestar la comunión, reconociendo un espacio preferencial para la realización y verificación de la comunión no ad intra de la Iglesia, como son las estructuras o los planes pastorales -sin desconocer su justo valor-, sino ad extra de la misma, en la evangelización, siguiendo la lógica de que un corazón misionero "nunca se encierra, nunca se repliega en sus seguridades, nunca opta por la rigidez autodefensiva” (EG 45).

Así, este modo de comprender la comunión hace posible, de manera "limpia" y "real", la unidad e integración de los distintos movimientos, parroquias, expresiones religiosas, en la única misión de la Iglesia, que es evangelizar, y que tiene múltiples modos. Por otro lado, libera a la estructura de una responsabilidad que no tiene. La comunión de la Iglesia, en efecto, no se verifica primeramente en sus estructuras, sin negar su contribución para ello, sino que ocurre en los "lugares de encuentro" con Cristo y, particularmente, en la misión, convocando a los diversos en torno a un objetivo común: la evangelización.

En síntesis, la propuesta de la "misión" como lugar de comunión visibiliza un paradigma nuevo donde la Iglesia, lejos de vivir curvada sobre sí misma, se abre a la pluralidad y diversidad que la constituye, favoreciendo que la comunión se verifique en la común tarea de todos, que es evangelizar.

\section{Estructuras misioneras}

Benedicto XVI afirmó en Verbum Domini que "la Iglesia no vive de sí misma, sino del Evangelio, y en el Evangelio encuentra siempre nueva orientación en su camino" (VD 51). En esta lógica, la propuesta de una Iglesia "en salida" provoca una "conversión pastoral" de toda ella a la misión (cf. EG 25s). 
Un signo de especial relevancia en este camino de conversión es la renovación de las estructuras eclesiales en vista a que

"[...] todas ellas se vuelvan más misioneras, que la pastoral ordinaria en todas sus instancias sea más expansiva y abierta, que coloque a los agentes pastorales en constante actitud de salida y favorezca así la respuesta positiva de todos aquellos a quienes Jesús convoca a su amistad". (EG 27).

La "conversión pastoral” cobra especial relevancia frente al ya enunciado "estructuralismo". Este fenómeno suele ser signo de una Iglesia instalada y, en no pocos casos, enferma, institucionalmente robusta pero vitalmente exigua o debilitada. Uno de los síntomas más conocidos de está "patología" pastoral son, por ejemplo, las abultadas "orgánicas" que complejizan el funcionamiento de la Iglesia, lo burocratizan y entorpecen la evangelización. Quienes son responsables de estas estructuras, en no pocas ocasiones, se ven obligados a estar más preocupados de la supervivencia de la estructura - de la "autopreservación"- que del sentido misionero y subsidiario de la misma.

En contraste, Evangelii Gaudium subraya que "cuando se asume un objetivo pastoral y un estilo misionero, que realmente llegue a todos sin excepciones ni exclusiones, el anuncio se concentra en lo esencial, que es lo más grande, lo más bello, lo más atractivo y, al mismo tiempo, lo más necesario" (EG 34). Esto implica que las estructuras eclesiales -que son medios para la evangelización- han de ser lo suficientemente "simples", dúctiles, con "poco personal" y "livianas" -que no es lo mismo que superfluas-, para que cumplan su función de ser facilitadoras de la misión, y estén siempre disponibles al cambio o a la desaparición, en caso de que queden obsoletas.

Porque la misión de la Iglesia es evangelizar, toda su orgánica ha de estar preparada para mutar las veces que sea necesario en vista a responder a la misión que justifica su existencia. Así, la opción de una Iglesia "en salida", provista de estructuras adecuadas para la misión, ha de ser capaz de transformarlo todo, para que las costumbres, los estilos, los horarios, el lenguaje y toda estructura eclesial estén al servicio del dinamismo misionero (cf. EG 27). Llevada esta óptica al ámbito parroquial, por ejemplo, queda aún más claro el paradigma propuesto por cuanto se afirma que la parroquia debe estar en "contacto con los hogares y con la 
vida del pueblo, y no se convierta en una prolija estructura separada de la gente o en un grupo de selectos que se miran a sí mismos” (EG 28).

La sentencia del Papa frente a la conversión de las estructuras es lapidaria:

"Más que el temor a equivocarnos, espero que nos mueva el temor a encerrarnos en las estructuras que nos dan una falsa contención, en las normas que nos vuelven jueces implacables, en las costumbres donde nos sentimos tranquilos, mientras afuera hay una multitud hambrienta y Jesús nos repite sin cansarse: ¡Dadles vosotros de comer! (Mc 6, 37)" (EG 49).

Discípulos en la intemperie

La V Conferencia de Aparecida -antecedente luminoso de Evangelii Gaudium-, subrayó que la Iglesia, peregrina en el Continente de la esperanza, es llamada a repensar las nuevas circunstancias latinoamericanas y mundiales "desde un encuentro personal y comunitario con Jesucristo" (DA 11). Y este llamado tiene una clara acentuación en el "discípulo misionero", porque esta tarea "no depende tanto de grandes programas y estructuras, sino de hombres y mujeres nuevos que encarnen dicha tradición y novedad, como discípulos de Jesucristo y misioneros de su Reino, protagonistas de vida nueva" (DA 11).

En esta senda, el reconocimiento de nuevos paradigmas de vida cristiana aparece como condición de posibilidad para el desarrollo de la propuesta eclesiológica y pastoral presentada. Y este paradigma parte del presupuesto de que "la nueva evangelización convoca a todos" (EG 14) y de que en "los bautizados, desde el primero hasta el último, actúa la fuerza santificadora del Espíritu que impulsa a evangelizar" (EG 119). En efecto, como se señaló precedentemente, el Bautismo ha hecho a todos los miembros del Pueblo de Dios discípulos provocados a la misión evangelizadora, buscando el modo "de comunicar a Jesús que corresponda a la situación en que nos hallemos" (EG 121). Al mismo tiempo, está lógica revela que ser discípulo es "tener la disposición permanente de llevar a otros el amor de Jesús y eso se produce espontáneamente en cualquier lugar” (EG 127).

Evidentemente, la propuesta ofrece un renovado paradigma de cristiano donde se revaloriza el trabajo y el testimonio que dan los bautizados, en la amplia gama de la cotidianidad, del saber, de las ciencias, de las artes, de la política, de la cultura, y se les anima a ser misioneros 
con el ardor del discípulo, comprendiendo que el Señor espera de ellos, testigos luminosos, competentes en lo propio y capaces de impregnar, con los criterios del Evangelio todas las dimensiones -hasta las más recónditas- de la existencia humana. Reconocer el valor de los cristianos, insertos en los areópagos de la postmodernidad, parece ser un fruto claro de esta novedosa e inclusiva perspectiva eclesiológico pastoral.

Pero lo señalado no implica una desvalorización del rol o de la misión de quienes son agentes pastorales. Su rol es insustituible. Pero no parece razonable que el paradigma de discípulo misionero se reduzca al de una persona que trabaje dentro de la estructura eclesial. Por otro lado, esta comprensión "ad intra", a nuestro parecer, muchas veces esconde un modo distinto de "clericalismo", dado que, de alguna manera, las tareas y acciones del ordenado son presentadas como "el" camino de santidad en la vida de la Iglesia, y por tanto, en la medida de que el laico se le asemeje, se acerca más a la plenitud cristiana.

Francisco sintetiza magistralmente lo señalado:

"La misión en el corazón del pueblo no es una parte de mi vida, o un adorno que me puedo quitar; no es un apéndice o un momento más de la existencia. Es algo que yo no puedo arrancar de mi ser si no quiero destruirme. Yo soy una misión en esta tierra, y para eso estoy en este mundo. Hay que reconocerse a sí mismo como marcado a fuego por esa misión de iluminar, bendecir, vivificar, levantar, sanar, liberar. Allí aparece la enfermera de alma, el docente de alma, el político de alma, esos que han decidido a fondo ser con los demás y para los demás" (EG 273).

\section{Conclusión: la Iglesia es una "Comunión misionera”}

Eclesiológicamente, la óptica de Evangelii Gaudium muestra una comprensión sugerente, asumiendo a la Iglesia como Misterio de Comunión, que encuentra su modelo de vida y de realización en la Trinidad. Pero, al mismo tiempo, entiende que esta comunión, lejos de todo intimismo, posee como rasgo esencial ser -como la Trinidad- totalmente abierta "para" participar su vida y su felicidad, "para" darse. Analógicamente a la situación del hombre que se realiza a partir de la "donación de sî", la Iglesia se plenifica proexistentemente, en su "extroversión", "fuera de sî́. Por eso, más precisamente, la Iglesia debe ser comprendida como una "Comunión misionera". 
Esta acentuación resulta original porque evidencia a la comunidad de los discípulos en un dinamismo de "salida", de donación gratuita al mundo; entrega que no es una mera actividad, sino una característica primordial de su ser. Ella sirve porque su misma naturaleza así lo exige. Por tanto, la comunión no es entendida como una experiencia interior o intimista, sino, muy por el contrario, como una común-unión que se proyecta en la misión.

Las consecuencias son evidentes. Una eclesiología de esta naturaleza configura una Iglesia amistosa y dialogante -que no es lo mismo que ingenua-, que discierne críticamente la realidad a la luz del Evangelio con la mirada del discípulo. No es su estructura, ni su funcionamiento los que consumen su vida y explican su comunión -aunque no se desconoce su valor-, sino que el rasgo fundamental que le da sentido a su ser Iglesia es la misión de construir el Reino y de brindar su generoso servicio al mundo para que más hombres conozcan la verdad sobre Jesús y la plenitud de lo humano.

Pastoralmente, las consecuencias no se dejan esperar. La prioridad no está en las reuniones que parecen dar testimonio de la comunión de los miembros de la Iglesia, ni en las evaluaciones, cuyos resultados suelen ser tardíos frente a un mundo que cambia vertiginosamente, ni en las discusiones acerca de las formas, los estilos, las relaciones internas o la participación, que insertan, a la Iglesia en un circuito "narcisista", sino que la prioridad está en la donación de la vida, que supone una Iglesia no "curvada" sobre sí misma, sino abierta al don y al consecuente servicio, comprometida toda entera con la evangelización, comprendiendo esta entrega y esta misión como el correlato existencial que explica -y da cuenta- de su misma identidad.

En un ámbito aún más acotado, esta propuesta de una Iglesia "en salida” exige una revisión de las modos de conducción de la Iglesia, del sentido y los alcances de las curias diocesanas, de las vicarías y los decanatos, y de todas las instituciones eclesiales, cuyo desarrollo, en no pocas ocasiones, las ha llevado a tener estructuras "pesadas", complejas, con pretensiones monopólicas y uniformes, que limitan el sentido evangelizador de la comunión diversa y misionera, que es la Iglesia. También esta propuesta provoca una conversión pastoral de las estructuras en vista a que sean subsidiarias de la acción pastoral de las comunidades vivas 
y al servicio de una acción evangelizadora tanto descentralizada como diversa.

Esta comprensión de Iglesia "en salida", también exige una mirada más flexible de lo "programático", de tal forma que los mismos itinerarios pastorales transiten desde "hojas de ruta" rígidas, y con fecha de caducidad temprana, a orientaciones con rasgos amplios, respetuosas de la rica diversidad de la Iglesia y profundamente centradas en relevar los lugares de encuentro con Cristo, de tal forma que los "diversos" -que son miembros de la misma Iglesia- puedan estar unidos en lo esencial y, al mismo tiempo, desarrollen una evangelización de acuerdo a su originalidad discipular, y a las exigencias concretas de su realidad.

En esta misma lógica, la maduración de los mecanismos de participación de los bautizados en las estructuras de la Iglesia, no deberían comprenderse solo en vista de la organización eclesial, sino prioritariamente para al servicio del "sueño misionero de llegar a todos" (EG 31). El paradigma del cristiano que emerge de esta propuesta, como oportunamente se señaló, es el testigo de Cristo que, inserto en la intemperie de la postmodernidad, da testimonio de lo atractivo que es el Evangelio y de la humanización que conlleva el camino que Cristo propone.

Con luminosa claridad, Francisco nos ha introducido en un dinamismo de "salida", que exige a la Iglesia una conversión pastoral que favorezca la diversidad, provocando la acción misionera de los discípulos y pretendiendo que estos, desde la riqueza y la originalidad de su bautismo, sean sujetos individuales y colectivos del anuncio del Evangelio en los diversos areópagos. También, ha insertado a la comunidad de los discípulos en un camino de conversión a la misión, donde los distintos miembros de la Iglesia, que son una comunión, se articulan en vista a la entrega generosa para la vida del mundo. 
